\title{
Perch, Perca fluviatilis show a directional preference for, but do not increase attacks toward, prey in response to water- borne cortisol
}

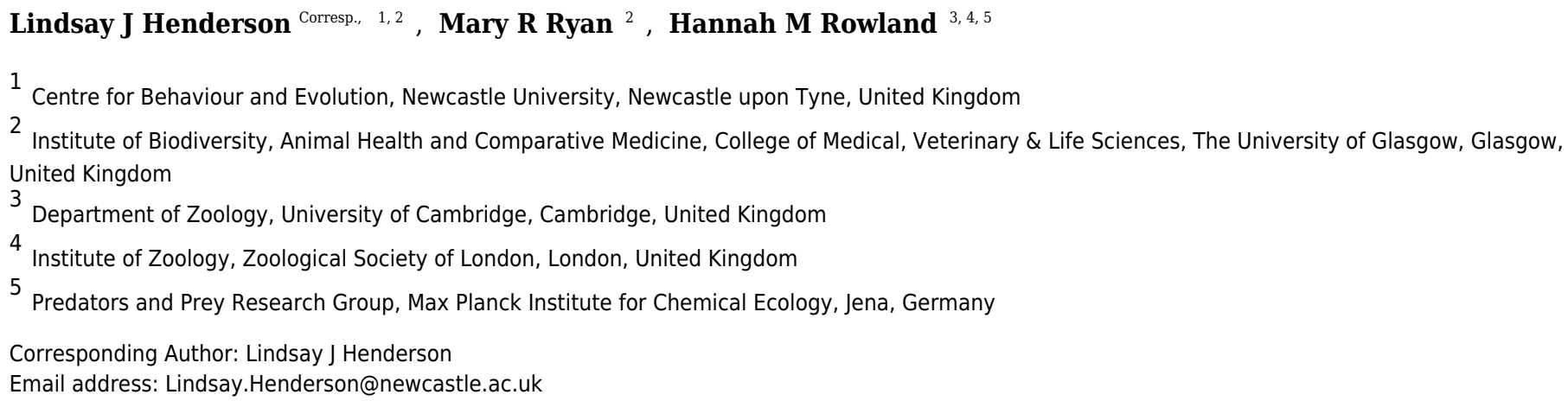

In freshwater environments, chemosensory cues play an important role in predator-prey interactions. Prey use a variety of chemosensory cues to detect and avoid predators. However, whether predators use the chemical cues released by disturbed or stressed prey has received less attention. Here we tested the hypothesis that the disturbance cue cortisol, in conjunction with visual cues of prey, elevates predatory behavior. We presented predators (perch, Perca fluviatilis) with three chemosensory choice tests and recorded their location, orientation, and aggressive behavior. We compared the responses of predators when provided with (i) visual cues of prey only (two adjacent tanks containing sticklebacks); (ii) visual and natural chemical cues of prey vs. visual cues only; and (iii) visual cues of prey with cortisol vs. visual cues only. Perch spent a significantly higher proportion of time in proximity to prey, and orientated toward prey more, when presented with a cortisol stimulus plus visual cues, relative to presentations of visual and natural chemical cues of prey, or visual cues of prey only. There was a trend that perch directed a higher proportion of predatory behaviors (number of lunges) toward sticklebacks when presented with a cortisol stimulus plus visual cues, relative to the other chemosensory conditions. But they did not show a significant increase in total predatory behavior in response to cortisol. Therefore, it is not clear whether water-borne cortisol, in conjunction with visual cues of prey, affects predatory behavior. Our results provide evidence that cortisol could be a source of public information about prey state and/or disturbance, but further work is required to confirm this. 


\section{Perch, Perca fluviatilis show a directional preference for, but do not}

\section{2 increase attacks toward, prey in response to water-borne cortisol}

4 Shot title: Hormonal cues and predation

5 Authors: Lindsay J. Henderson* 1,2, Mary R. Ryan² and Hannah M. Rowland ${ }^{3,4,5}$

6

7

81 Centre for Behaviour and Evolution, IoN, Newcastle University, Henry Wellcome Building,

$9 \quad$ Framlington Place, Newcastle, UK

102 Institute of Biodiversity, Animal Health and Comparative Medicine, College of Medical,

11 Veterinary \& Life Sciences, The University of Glasgow, Glasgow, UK

123 Department of Zoology, University of Cambridge, Cambridge, UK

134 Institute of Zoology, Zoological Society of London, Regents Park, London, UK

145 Predators and Prey Research Group, Max Planck Institute for Chemical Ecology, Jena, 15 Germany

16

17

18 *Corresponding author: Lindsay J. Henderson

19 Email: Lindsay.Henderson@ncl.ac.uk

20 


\section{Abstract}

22 In freshwater environments, chemosensory cues play an important role in predator-prey 23 interactions. Prey use a variety of chemosensory cues to detect and avoid predators. However, 24 whether predators use the chemical cues released by disturbed or stressed prey has received less 25 attention. Here we tested the hypothesis that the disturbance cue cortisol, in conjunction with 26 visual cues of prey, elevates predatory behavior. We presented predators (perch, Perca 27 fluviatilis) with three chemosensory choice tests and recorded their location, orientation, and 28 aggressive behavior. We compared the responses of predators when provided with (i) visual cues 29 of prey only (two adjacent tanks containing sticklebacks); (ii) visual and natural chemical cues of 30 prey vs. visual cues only; and (iii) visual cues of prey with cortisol vs. visual cues only. Perch 31 spent a significantly higher proportion of time in proximity to prey, and orientated toward prey 32 more, when presented with a cortisol stimulus plus visual cues, relative to presentations of visual 33 and natural chemical cues of prey, or visual cues of prey only. There was a trend that perch 34 directed a higher proportion of predatory behaviors (lunges) toward sticklebacks when presented 35 with a cortisol stimulus plus visual cues, relative to the other chemosensory conditions. But they 36 did not show a significant increase in total number of lunges in response to cortisol. Our results 37 provide tentative evidence that cortisol affects predatory behavior, and could be a source of 38 public information about prey state and/or disturbance, but further work is required to confirm 39 this. 


\section{Introduction}

41 The outcomes of predator-prey interactions are largely influenced by the ability of predators and 42 prey to detect and respond to one another (Lima \& Dill, 1990; Endler, 1991). An organism that 43 perceives a predatory threat or potential prey before being detected itself gains an advantage 44 (Lunt \& Smee, 2015). Prey can successfully avoid predators when they have the sensory 45 advantage by detecting and avoiding predators before being consumed (Mirza \& Chivers, 46 2002). In contrast, predators prevail when they hold the perceptual advantage and detect prey 47 before they are themselves detected and prey can escape. There is a built-in imbalance between 48 predator and prey in regard to the penalty of failure during an encounter: failure for prey is death, 49 whereas for a predator it is only a lost meal (Dawkins \& Krebs, 1979). This asymmetry in the 50 selective pressure on predators and prey, known as the 'life-dinner' principle (Dawkins \& Krebs, 51 1979), is reflected in the greater research attention afforded to prey responses over predator 52 behavior (Ferrari, Wisenden \& Chivers, 2010). A greater understanding of how predators 53 respond to cues released by prey could provide greater insight into the selective forces that shape

54 the evolution of predator-prey interactions.

55

56 Predators and prey use cues across multiple sensory channels to detect one another, including 57 visual, acoustic, chemical, electrical and/or tactile cues (Ferrari, Wisenden \& Chivers, 2010). In 58 aquatic systems chemical cues are a principal source of information (DeBose \& Nevitt, 2008; 59 Ferrari, Wisenden \& Chivers, 2010). Prey increase anti-predator behaviors in response to the 60 chemical cues of predators (e.g., kairomones Ferrari, Wisenden \& Chivers, 2010), as well as the 61 chemical cues released by prey that have been injured by predators (e.g., damage-released alarm 62 cues, Mathis \& Smith, 1993; Harvey \& Brown, 2004; Chivers, Brown \& Ferrari, 2012; 
63 Lonnstedt, McCormick \& Chivers, 2012), and by prey that have been disturbed or stressed by

64 predators, without being injured or consumed (e.g. disturbance cues, Chivers, Brown \& Smith,

65 1996; Vavrek et al., 2008; Vavrek \& Brown, 2009; Ferrari, Wisenden \& Chivers, 2010; Brown et

66 al., 2012). By responding to the chemical cues of heterospecifics and conspecifics, about the

67 presence of predators, prey have increased chances of survival during encounters with predators

68 (Mirza \& Chivers, 2002).

69

70 Predators detect and respond to damage-released alarm cues to localize prey (Mathis, Chivers \&

71 Smith, 1995; Wisenden \& Thiel, 2002; Lönnstedt, McCormick \& Chivers, 2012). While this

72 suggests that the release of damage-released alarm cues would be detrimental for prey, research

73 into the responses of predators have revealed additional fitness benefits to prey (Chivers, Brown

74 \& Smith, 1996; Lönnstedt \& McCormick, 2015). Prey that release alarm cues after injury attract

75 secondary predators, which increases their probability of surviviving the encounter by $35-40 \%$

76 (Lönnstedt \& McCormick, 2015). Therefore, investigating the responses of predators can provide

77 insight into the selective dynamics acting on both cues and the producers of cues (Mathis,

78 Chivers \& Smith, 1995; Chivers, Brown \& Smith, 1996; Lönnstedt \& McCormick, 2015).

79

80 In contrast, whether predators respond to disturbance cues released by prey has received less

81 attention (Chivers, Brown \& Ferrari, 2012). Disturbance cues are interesting because prey could

82 have more control over their release (Chivers, Brown \& Ferrari, 2012), in comparison to

83 damage-released alarm cues that are released after injury. Disturbance cues could benefit both

84 prey and predators if their release reliably informs predators that they have been detected and are

85 therefore less likely to be successful in capturing prey (e.g. pursuit deterrent, Woodland, Jaafar \& 
86 Knight, 1980; Caro, 1995). However, if predators can detect and use disturbance cues to localize

87 prey, selection could act to reduce their release by prey in environments with a high density of 88 predators. Therefore, disturbance cues are predicted to have more diverse selection pressures 89 acting on them than damage-released alarm cues (Chivers, Brown \& Ferrari, 2012).

91 Disturbance cues exist in a variety of systems, including invertebrates, amphibians, and 92 freshwater fish (Hazlett, 1990; Wisenden, Chivers \& Smith, 1995; Kiesecker et al., 1999; Bryer, 93 Mirza \& Chivers, 2001; Mirza \& Chivers, 2002; Jordão, 2004; Brown et al., 2012). It has been 94 suggested that nitrogenous compounds in urine, and respiratory byproducts could act as 95 disturbance cues (Hazlett, 1990; Kiesecker et al., 1999; Vavrek \& Brown, 2009; Brown et al., 96 2012). One potential disturbance cue that has received less research attention is the stress 97 hormone cortisol (Olivotto et al., 2002; Vavrek \& Brown, 2009), the principal glucocorticoid in 98 teleost fish (Brown, Gardner \& Braithwaite, 2005). Prey fish show an acute elevation of their 99 circulating cortisol concentrations in response to the presence of predators (Breves \& Specker, 100 2005; Barcellos et al., 2007). Cortisol can pass across the gills into the surrounding water (Scott 101 \& Ellis, 2007; Sebire, Katsiadaki \& Scott, 2007), and can influence the physiological stress 102 responses of conspecifics (Toa, Afonso \& Iwama, 2004; Barcellos et al., 2011). Elevated cortisol 103 concentrations are associated with reduced body mass and growth, as well as increased parasite 104 loads in fish species (Jentoft et al., 2005; Fast et al., 2006). These factors in turn have been 105 linked to reduced predator avoidance in prey (Sogard, 1997; Ness \& Foster, 1999). It is therefore 106 possible that cortisol could provide information about prey state and/or disturbance, and that 107 predators could become attuned to this physiological response of prey. Whether predators can 108 detect and respond to the presence of cortisol released by prey or use the presence of the 
109 hormone to inform their foraging decisions is unknown. This is an important gap in our

110 knowledge because if predators can eavesdrop upon disturbance cues and use them to localize

111 prey, this could influence the selective advantage of the release of disturbance cues by prey

112 (Ferrari, Wisenden \& Chivers, 2010).

113

114 To answer this question, we investigated whether predators respond specifically to cortisol,

115 and/or other 'signature' chemical cues released by prey (Wyatt, 2010), when also presented with

116 visual cues of prey. We used the piscivorous European perch (Perca fluviatilis) as model

117 predator, and three-spined stickleback (Gasterosteus aculeatus) as prey. We presented each

118 perch with three chemosensory prey choice tests (i) visual cues only of two adjacent tanks

119 containing sticklebacks; (ii) visual and natural chemical cues of sticklebacks on one side vs.

120 visual cues only on the other; and (iii) visual cues of sticklebacks with a cortisol stimulus on one

121 side vs. visual cues only on the other (Fig. 1). We predicted that, (a) if predators use cortisol to

122 identify and localize prey, predators should show a preference for prey associated with cortisol

123 over prey without the chemical cue; or (b) if predators use cortisol as a signal of vigilant prey

124 and reduced likelihood of attack success, predators should reduce their preference for prey with

125 the cortisol cue. For both behavioral responses, if it is cortisol specifically that attracts predators

126 we predict their response to be similar if cortisol is presented alone, or with additional chemical

127 cues of sticklebacks. Alternatively, (c) our null hypothesis was that perch would not show a

128 preference for prey when visual cues are augmented with the chemical cue cortisol.

129

130 Materials and Methods 
131 All fish were collected from water-bodies in west central Scotland. Three-spined sticklebacks $(n$

$132=150, \sim 1 \mathrm{~g}$ ) were collected in October-November 2011 from Balmaha Pond, a small water body

133 that does not contain piscivorous fish. Perch $(\sim 16-20 \mathrm{~cm}$ length, $52.5 \pm 9.8 \mathrm{~g})$, a natural predator of

134 sticklebacks (Gross, 1978), were collected in October 2010 and 2011 from Howend Trout

135 Fishery. Perch were likely to have had experience of sticklebacks at Howend Trout Fishery. Fish

136 were housed at indoor aquaria at the University of Glasgow, UK. Fish were fed daily with frozen

137 bloodworm (Glycera dibranchiate), and kept under a light regime of 12L:12D. Mains tap water

138 was used for holding water and water temperature was $16.5 \pm 1^{\circ} \mathrm{C}$ with a $\mathrm{pH}$ of $8-8.4$. All

139 experiments were conducted between December 2011 and January 2012, using a tank design that

140 allows transfer of chemical and visual cues between fish (Le Vin, Mable \& Arnold, 2010), while

141 preventing physical interaction for ethical reasons (Fig. 1, Animal Behaviour, 2006).

142

\section{Experimental procedure}

144 Each perch was introduced into a $45 \times 20 \times 25 \mathrm{~cm}$ experimental tank $\sim 20 \mathrm{~h}$ before a test to allow for

145 acclimation after handling, and to standardize hunger between individuals. Adjacent to the 146 experimental tank on either side were two flow-through stimulus tanks $(10 \times 20 \times 25 \mathrm{~cm})$, each

147 maintained with 21 of water. Five sticklebacks were introduced into each stimulus tank, also

$148 \sim 20 \mathrm{~h}$ before a test. Flow-through stimulus tanks were used to avoid accumulation of cortisol in

149 the water during acclimation, caused by capture and handling and due to the small size of tanks

150 (Pottinger et al., 2011; Archard et al., 2012). Removable opaque barriers were positioned

151 between the experimental and stimulus tanks to prevent the perch and sticklebacks from seeing

152 each other during acclimation. These were removed at the start of a test to allow predators and 153 prey to see one another. 
155 To test the influence of hormonal cues on predator behavior, each perch participated in three 156 chemosensory choice tests (number of perch $=18$, total number of tests $=54$ ): (i) a control test, 157 where fresh water was dripped into the perch tank on both sides directly in front of the stimulus 158 tanks holding sticklebacks (Fig. 1a); (ii) a natural chemical test, where water from one of the 159 stimulus tanks containing naïve sticklebacks (no previous exposure to perch) was dripped into 160 one side and fresh water dripped into the other (Fig. 1a and b); and (iii) a cortisol test, where we 161 provided our putative disturbance cue at a concentration that a predator might encounter in 162 nature $(0.2 \mathrm{ng} / \mathrm{ml}$ of free cortisol; Sigma) on one side and fresh water on the other (Fig. 1a). 163 Sticklebacks have been documented to release up to $0.26 \mathrm{ng} / \mathrm{ml} / \mathrm{hr}$ cortisol into holding water 164 after capture and handling (Sebire, Katsiadaki \& Scott, 2007; Pottinger et al., 2011). Because 165 perch are diurnal visual predators, in all tests predators were given visual cues of sticklebacks.

166 Visual cues were provided on both sides of the perch's tank and only chemical cues changed 167 between tests.

168

169 The order of chemosensory tests and the side placement of the chemical stimulus were 170 randomized. Water was drawn from neighboring stimulus tanks through a pump system with a 171 flow rate of $1.6 \mathrm{ml} / \mathrm{min}$, which has been shown to induce a reaction to the chemical stimulus in 172 other fish species (McLennan \& Ryan, 1997; Le Vin, Mable \& Arnold, 2010). A previous study 173 has shown using color-dyed water, that water dripped into a focal tank remained mainly 174 localized within the zone $(13 \times 8 \times 19)$ immediately adjacent to where the water was dripped (Le 175 Vin, Mable \& Arnold, 2010). 
177 In the natural chemical tests, sticklebacks had not been used previously in the experiment

178 (naïve). Our rationale here was that they would show a natural stress response and release

179 elevated levels of cortisol, after visual exposure to perch (Barcellos et al., 2007). Sticklebacks

180 were in some cases re-used in the other two tests to reduce the total number of sticklebacks used

181 in the experiment (in line with the 3Rs Animal behaviour, 2006). Sticklebacks were not used on

182 consecutive days or more than twice a week, as per the terms of our Home Office licence. In a

183 sub-sample of stickleback tanks $(n=17$ tanks containing 5 sticklebacks; 9 were naïve, 8 were re-

184 used) we found no difference in the time the sticklebacks spent in the side of the tank closet to

185 the perch (GLM $t=1.09, P=0.29)$, or the maximum number that nipped at perch (GLM $t=$ $1860.98, P=0.33)$, between naïve and re-used tanks of sticklebacks.

187

188 At the start of each test the opaque barriers were removed, the stimulus pumps were started and 189 the flow-through system in the stimulus tanks was stopped. We observed the perch for $60 \mathrm{~min}$ 190 from behind a blind to avoid any effect of the observer on fish behavior. We visually divided the 191 perch tank into three equal zones (15cm length), two 'preference zones' (chemical stimulus zone 192 and the opposite non-chemical stimulus zone) located adjacent to the front of each stimulus tank 193 and a 'non-preference' zone in between them (Fig. 1). For analysis in the control tests where 194 there were no chemical stimuli, the chemical stimulus zone was allocated to the left side in $50 \%$ 195 of tests and to the right for the other $50 \%$.

196

197 We used Observer 8 software to record the duration spent by perch in each zone; the duration 198 spent orientating toward sticklebacks in each zone; the number of predatory attacks made toward 199 the sticklebacks (hereon termed lunges, which were defined as rapid forward movements toward 
200 sticklebacks). We also counted the number of times fish moved between zones to quantify their

201 level of activity. At the end of the $60 \mathrm{mins}$ the perch and sticklebacks were returned to their

202 holding tanks, and the experimental tanks that held perch and sticklebacks were then drained and

203 cleaned before their use in the next test. Each perch had a two day break between tests.

204

\section{Cortisol concentration in experimental tanks}

206 To assess the concentration of cortisol released by stickleback into their holding water we 207 collected the water from their tanks in the natural chemical cue tests, $60 \mathrm{~min}$ after presentation of 208 the perch $(n=9)$. To measure the level of cortisol released by perch into their holding water in 209 the experimental tanks, we collected water after 60 mins when no stimulus water was being 210 pumped $(n=4)$.

212 To determine the cortisol concentrations in the water samples, cortisol was extracted by pulling $213100 \mathrm{ml}$ under vacuum at a rate of ca. $5 \mathrm{ml} / \mathrm{min}$ through primed SPE cartridges containing 214 octadecylsilane (Sep-pak Plus, Waters Ltd., Watford, UK). Water samples were not pre-filtered. 215 Priming involved $5 \mathrm{ml}$ methanol followed by $5 \mathrm{ml}$ distilled water. After the samples had been 216 pulled through, the cartridges were washed with $5 \mathrm{ml}$ distilled water followed by $20 \mathrm{ml}$ air (to 217 remove as much moisture as possible). The free steroids (not conjugated (Ellis et al., 2004)) were 218 eluted with $5 \mathrm{ml}$ ethyl acetate. These were collected in a glass tube and evaporated at $45^{\circ} \mathrm{C}$ under 219 a stream of air. Samples were then re-suspended in $250 \mu$ l of assay buffer (Tris-buffered saline) 220 and cortisol concentrations were established using a Cortisol ELISA Kit (Enzo Life Sciences,

221 Inc.). Samples were run within two assays, all samples run in triplicate and recoveries calculated 222 after a known amount of cortisol was added to samples were $>96 \%$ and the mean intra-and inter- 
223 assay coefficient of variation were $8.6 \%$ and $8.4 \%$ respectively. $100 \mathrm{ml}$ water samples were used

224 because cortisol is found at low concentrations in holding water (Scott \& Ellis, 2007), and this

225 methodology allowed the amount of cortisol to be concentrated so that values could be measured

226 on the linear phase of the standard curve (sample value range: $14.2-4.4 \mathrm{ng} / \mathrm{ml}$, standard curve:

$227100-0.78 \mathrm{ng} / \mathrm{ml})$. As the $100 \mathrm{ml}$ water samples were re-suspended in $250 \mu 1$ of buffer for the assay

228 (x400 concentration), cortisol values from the assay were divided by 400 to give the

229 concentration in the holding water $(\mathrm{ng} / \mathrm{ml})$.

230

231 Statistical analyses

232 To investigate whether perch behavior differed between the three chemosensory choice tests, we

233 calculated the proportion of total time that perch spent in the chemical stimulus zone, the

234 proportion of time that perch spent orientating toward the sticklebacks in the chemical stimulus

235 zone, and the proportion of total lunges at sticklebacks in the chemical stimulus zone. We

236 calculated proportions because we were comparing between choice tests. We calculated

237 proportions as the time spent in the chemical stimulus zone divided by the sum of the time spent

238 in all zones. We calculated the proportion of time orienting toward sticklebacks using the same

239 method. For lunges at sticklebacks we calculated the proportion of lunges in the chemical

240 stimulus zone divided by the sum of lunges in the chemical stimulus zone and the opposite

241 stimulus zone (visual cues only). All proportions were arcsine-transformed to normalize data.

243 Linear Mixed Models (LMMs) were used to assess whether chemosensory test type (control,

244 natural cues, cortisol) influenced the proportion of time spent in the chemical stimulus zone, the

245 proportion of time orienting in the chemical stimulus zone, and the proportion of lunges by perch 
246 at sticklebacks in the chemical stimulus zone. We also used a LMM to test whether the number

247 of movements perch made around their tank differed between chemosensory tests (although

248 these data were a count they were normally distributed). We used Generalized Linear Mixed

249 Models (GLMMs) to investigate whether total lunges at sticklebacks differed between

250 chemosensory tests with a negative binomial error structure (due to overdispersion). Perch

251 identity was included as a random factor in all models to account for repeated measures. To

252 control for multiple tests, we applied a Bonferroni correction to our level of statistical

253 significance: effects were only considered significant if $P<0.01$.

254

255 The order in which chemosensory tests were presented to perch did not influence their behavior $256(P>0.70)$, and so this factor was not included in final models. Chemosensory test type did not 257 affect whether perch began the test in the chemical stimulus zone (binomial GLMM $z=0.76, P=$ 258 0.45). We analyzed whether chemosensory test affected if perch were active or remained 259 immobile during the 60min observation using a binomial GLMM. We then split our analyses, to 260 focus on actively behaving perch for all behavioral analysis (where perch showed at least one 261 behavior: $n=$ control, 16; natural cues, 15; cortisol, 11). We removed immobile individuals 262 because at the start of each trial a perch could be located in any zone within the tank: if the focal 263 perch did not move for the entire test, the perch would be assigned $100 \%$ of time to a single 264 zone, and $100 \%$ of time orientating in a single direction. This would necessarily have skewed our 265 data. For the proportion of lunges, we did not include perch that did not lunge, and thus 266 contributed zeros $(n=6)$. This is because a zero value could be perceived incorrectly as $100 \%$ of 267 lunging behavior occurring at the opposite stimulus zone ( $n=$ control, 14 ; natural cues, 13; 268 cortisol, 9). 
270 All analyses were conducted using the nlme package, and the lme4 package for GLMMs in R

2712.12 .2 ( $\mathrm{R}$ core team 2012). The data used for analyses can be found in supporting information 272 S1.

273

\section{Ethics statement}

275 This study was performed under a UK Home Office licence (60/4292) and was subject to review 276 by the University of Glasgow ethics committee. All experiments were conducted using a tank 277 design that allows transfer of chemical and visual cues between fish, while preventing physical 278 interaction for ethical reasons. The hormone concentrations used in this study are within the 279 natural levels experienced by fish in the wild. Prey fish were provided with shelter while in 280 visual contact with the predator. Permission to catch perch was granted by a privately-owned 281 trout fishery (Howend) and sticklebacks were collected from Balmaha pond after obtaining 282 permission from the Scottish government. This study did not involve endangered or protected 283 species.

284

285 Results

\section{Predator behavior}

287 Of the 18 perch, 9 did not move during an entire test ( $n=12$ out of 54 tests), and this was 288 marginally, but non-significantly, more likely to occur in trials when cortisol was the chemical 289 cue (binomial GLMM $z=1.82, P=0.06$ ).

291 When we focus on actively moving individuals, perch spent a significantly higher proportion of 
292 their time in the chemical stimulus zone when cortisol was added compared to natural chemical

293 cues of sticklebacks and the water control (Table 1 \& Fig. 2a). Perch also oriented toward

294 sticklebacks for a significantly higher proportion of time in the chemical stimulus zone when

295 cortisol was added compared to natural chemical cues of sticklebacks and the water control

296 (Table 1 \& Fig. 2b). There was a marginally non-significant trend for perch to show a higher

297 proportion of lunges toward sticklebacks in the chemical stimulus zone when cortisol was added,

298 compared to the water control (Table 1 \& Fig. 2c). Perch did not lunge more overall at

299 sticklebacks in the chemical stimulus zone during the cortisol tests compared to the other

300 chemosensory tests (Fig. 3a, GLMM $z=-0.35, P=0.73$ ). Perch moved around the tank equally

301 frequently in each chemosensory test (Fig. 3b, LMM $t=0.38, P=0.70$ ).

302

303 When we analyze perch behavior including only those perch that were active under all three 304 treatments (9 perch, and 27 trials) our results are consistent with previous analysis. (Proportions: 305 Duration, GLMM $t=3.62, P=0.002$; Orienting, GLMM $t=3.91, P<0.001$, Lunges, LMM $t=$ 306 1.87, $P=0.08$. Total lunges: GLMM $z=0.27, P=0.78)$.

307

308 Concentration of cortisol in experimental tanks

309 The mean concentration of cortisol in the natural chemical tests was an order of magnitude lower 310 than the cortisol test; $0.02 \mathrm{ng} / \mathrm{ml}($ S.E. $<0.001)$ vs. $0.2 \mathrm{ng} / \mathrm{ml}$, and was lower than the mean 311 concentration of cortisol in the perch holding water; $0.05 \mathrm{ng} / \mathrm{ml}($ S.E. $<0.001)$.

\section{Discussion}

314 We predicted that the disturbance cue cortisol would affect our predators' behavior toward prey, 
315 manifesting as either an increased attraction to or avoidance of prey. Our results support both the

316 attraction and deterrence hypothesis. We found that our predators spent more time in close

317 proximity to prey, as well as more time oriented toward prey, when prey were associated with

318 cortisol. To our knowledge, this is the first evidence that water-borne cortisol can increase

319 interest toward prey. Our results are in line with the findings of other research that has shown

320 predators are attracted to, and use damage-released alarm cues to detect prey (Chivers, Brown \&

321 Smith, 1996; Wisenden \& Thiel, 2002; DeBose \& Nevitt, 2008; Ferrari, Wisenden \& Chivers,

322 2010; Elvidge \& Brown, 2012; Lönnstedt, McCormick \& Chivers, 2012). However, while there

323 was a trend that perch showed a higher proportion of attacks toward prey in the cortisol test,

324 perch did not show a statistically significant increase in total attacks toward prey in the cortisol

325 tests. We also observed that some of our predators were immobile throughout a test, and that this

326 was marginally more likely to occur in response to prey associated with cortisol. Therefore, it is

327 unclear whether cortisol is strictly involved in predatory behavior. The observed immobility

328 could be a deterrence effect of cortisol, i.e. that perch perceived cortisol as a cue of prey

329 vigilance (Woodland, Jaafar \& Knight, 1980; Smith, 1992). Alternatively, immobility could be

330 an antipredator response by our predators.

332 Responding to cortisol may aid predators in localizing prey. In addition, higher levels of cortisol 333 associated with prey may indicate that they have a reduced ability to avoid predators, as 334 elevated cortisol has been found in fish in poorer condition (Sogard, 1997; Ness \& Foster, 1999). 335 Alternatively, avoidance of cortisol by predators could be advantageous if it indicates that they 336 have been detected and prey are vigilant (Woodland, Jaafar \& Knight, 1980), or that other 337 predators are foraging in an area (Olsson \& Brown, 2006). The presence of cortisol could also 
338 indicate a predator's own predation risk. Predators may respond differently to chemical cues of

339 prey depending upon their life-history stage or prior experience. For example, in yellow perch

340 (Perca flavescens) there is an ontogenetic shift from insectivory to piscivory, and this is

341 associated with contrasting responses to the skin extracts of conspecifics: adult perch increase

342 their foraging behavior in response to the skin extracts of conspecifics, while juveniles elevate

343 their anti-predator behavior (Harvey \& Brown, 2004). Our results do not provide unequivocal

344 evidence that water-borne cortisol specifically influences predatory behavior. As wild caught

345 perch were used, we were unable to control for their prior experience before capture. This could

346 have influenced their behavioral response to the chemical cue cortisol. To further understand the

347 behavioral responses of predators to the disturbance cue cortisol, it may be important to use

348 predatory fish that are reared in captivity to control for experience. Furthermore, research into

349 the behavioral responses of non-predatory fish to cortisol, and the response of predators to 350 cortisol in the presence of conspecifics are required. This would confirm that behavioral changes

351 are predatory and not a general response to cortisol.

352

353 A limitation of our study is that the sticklebacks we used as prey released less cortisol into their

354 holding water following visual exposure to a predator than sticklebacks that have experienced

355 handling stress (Sebire, Katsiadaki \& Scott, 2007; Pottinger et al., 2011). This is likely because

356 our sticklebacks originated from a water body that did not contain piscivorous fish. Many prey

357 species do not show innate recognition of potential predators (Mathis, Chivers \& Smith, 1993;

358 Chivers \& Smith, 1994), so a lack of experience of predatory fish may explain the low level of

359 stress response. Also, prey species often require chemical and/or mechanical stimuli in addition

360 to visual cues to respond to the presence of a predator (Stauffer \& Semlitsch, 1993; Breves \& 
361 Specker, 2005; Barcellos et al., 2007), which could further explain our findings. We suggest that

362 the lower level of cortisol in the natural cues test is why our predators did not show a difference

363 in their behavior in the natural chemical test compared to the water control. But due to this

364 limitation, we were unable to examine whether perch showed a preference for visual cues of 365 sticklebacks associated with both elevated cortisol and natural "signature" chemical cues (Wyatt, 366 2010). We could have added cortisol to the natural cues test, but as we had anticipated that the 367 sticklebacks in the natural cues test would show a cortisol response after visual exposure to the 368 perch (Barcellos et al., 2007), we assumed that doing this would have elevated cortisol to 369 ecologically irrelevant high levels $(>0.46 \mathrm{ng} / \mathrm{ml})$. Despite this limitation, we did show that 370 predators respond to cortisol over the natural chemical cues (e.g. nitrogenous compounds in 371 urine, and respiratory by-products) the prey fish released while visually exposed to predators. 372 Future experiments with predator-experienced prey would be worthwhile.

374 We also did not test whether perch showed a behavioral response to chemical cues alone. As 375 perch are sight-dependent diurnal predators, they likely require both visual and chemical cues to 376 target prey (Turesson \& Brönmark, 2004; Elvidge \& Brown, 2012). Although chemical-cue-only 377 tests could have provided information on the relative importance of visual and chemical cues, 378 our design still allowed us to investigate how chemical cues augment the behavior of predators in 379 comparison to visual cues only.

381 If predators only respond to cortisol when it rises above the background levels of cortisol, as 382 proposed in the background noise hypothesis (Vavrek and Brown 2009), then we would only 383 have detected behavioral changes in predators if sticklebacks produced more than the 
384 background level of $0.05 \mathrm{ng} / \mathrm{ml}$. The concentration used in our cortisol tests, was higher than the

385 background levels and was within the range released by sticklebacks after a handling stress

386 (Sebire, Katsiadaki \& Scott, 2007; Pottinger et al., 2011). Therefore, this concentration could be

387 experienced by perch in the wild, so should be biologically meaningful (Sebire, Katsiadaki \&

388 Scott, 2007; Pottinger et al., 2011). In a real world setting, cortisol is likely to be ubiquitous

389 within the environment (Hazlett, 1990; Kiesecker et al., 1999; Ferrari, Wisenden \& Chivers, 390 2010), as is the case for nitrogenous waste products that also act as disturbance cues (Hazlett, 391 1990; Kiesecker et al., 1999; Ferrari, Wisenden \& Chivers, 2010; Brown et al., 2012). Therefore, 392 the background level of cues could dictate how much cue is required to elicit a response. 393 Although the background noise hypothesis relates to prey behavior, we show it may also apply to 394 predators.

395

396 An alternative explanation for our results is that cortisol does not increase predatory behaviors 397 per se, but that it elevated the endogenous cortisol levels in our perch due to uptake of the water398 borne cortisol across the gills (Scott \& Ellis, 2007). Glucocorticoids are known to rapidly affect 399 activity patterns and aggressive behavior (Moore \& Evans, 1999; Øverli, Kotzian \& Winberg, 400 2002; Chang et al., 2012). However, active perch moved around the tank a similar amount during 401 each chemosensory test, and it was specifically inspection that were elevated in the cortisol tests 402 of actively moving perch.

403

404 The behavioral response of perch to a cortisol stimulus suggests that the hormone could 405 influence predatory behavior. Therefore, there is the intriguing potential of a chemosensory arms 406 race between predator and prey. Populations of sticklebacks differ in their behavioral profiles 
407 due to predation pressure (Bell, 2005; Bell \& Sih, 2007), and fish from high predation

408 populations have been shown to have a lower cortisol release rate than those from low predation

409 populations (Archard et al., 2012). This has been suggested to be beneficial as it could prevent

410 excessive energy expenditure due to repeated stress responses caused by the presence of

411 predators (Brown, Gardner \& Braithwaite, 2005). However, a reduced stress response could have

412 evolved due to predators selectively predating individuals that have a higher stress response.

\section{Conclusions}

415 Traditionally, research has focused on the function of the stress response experienced by prey 416 animals during a predation event. However, in this study we show how an improved 417 understanding of how predators respond to the stress responses of their prey could be useful 418 when investigating the complexity of predator-prey interactions. 


\section{Acknowledgments}

420

421 We thank Nick Beevers, David Fettes and Stuart Wilson for help with fish collection; Shaun

422 Killen, John Laurie and Donald Reid for help with experiment logistics and Colin Adams and

423 Neil Metcalfe for valuable advice. We thank Robert Burriss for comments on an earlier draft, 424 and two anonymous reviewers for their constructive feedback.

425 
Animal Behaviour. 2006. Guidelines for the treatment of animals in behavioural research and teaching. In: 225-245.

Archard GA., Earley RL., Hanninen AF., Braithwaite VA. 2012. Correlated behaviour and stress physiology in fish exposed to different levels of predation pressure. Functional Ecology

430

431

432 26:637-645. DOI: 10.1111/j.1365-2435.2012.01968.x.

Barcellos L., Ritter F., Kreutz L., Quevedo R., Dasilva L., Bedin A., Finco J., Cericato L. 2007. Whole-body cortisol increases after direct and visual contact with a predator in zebrafish, Danio rerio. Aquaculture 272:774-778. DOI: 10.1016/j.aquaculture.2007.09.002.

435

436

437

438

439

440

441

442

443

444

445

446

447

448

449

450

451

452

453

454

455

456

457

458

459

460

461

462

463

464

465

466

467

468

469

Barcellos L., Volpato GL., Barreto RE., Coldebella I., Ferreira D. 2011. Chemical communication of handling stress in fish. Physiology \& Behavior 103:372-375. DOI: http://dx.doi.org/10.1016/j.physbeh.2011.03.009.

Bell AM. 2005. Behavioural differences between individuals and two populations of stickleback (Gasterosteus aculeatus). Journal of Evolutionary Biology 18:464-473.

Bell AM., Sih A. 2007. Exposure to predation generates personality in threespined sticklebacks (Gasterosteus aculeatus). Ecology Letters 10:828-834.

Both C., Artemyev A V., Blaauw B., Cowie RJ., Dekhuijzen AJ., Eeva T., Enemar A., Gustafsson L., Ivankina E V., Jarvinen A., Metcalfe NB., Nyholm NE., Potti J., Ravussin PA., Sanz JJ., Silverin B., Slater FM., Sokolov L V., Torok J., Winkel W., Wright J., Zang H., Visser ME. 2004. Large-scale geographical variation confirms that climate change causes birds to lay earlier. Proceedings of the Royal Society B-Biological Sciences 271:1657-1662. DOI: 10.1098/rspb.2004.2770J14VL6QHGKG64983 [pii].

Breves JP., Specker JL. 2005. Cortisol stress response of juvenile winter flounder (Pseudopleuronectes americanus, Walbaum) to predators. Journal of Experimental Marine Biology and Ecology 325:1-7. DOI: http://dx.doi.org/10.1016/j.jembe.2005.04.019.

Brown C., Gardner C., Braithwaite VA. 2005. Differential stress responses in fish from areas of high- and low-predation pressure. Journal of Comparative Physiology B 175:305-312. DOI: 10.1007/s00360-005-0486-0.

Brown GE., Jackson CD., Malka PH., Jacques É., Couturier M-A. 2012. Disturbance cues in freshwater prey fishes: Does urea function as an "early warning cue" in juvenile convict cichlids and rainbow trout? Current Zoology 58:250-259.

Bryer PJ., Mirza RS., Chivers DP. 2001. Chemosensory assessment of predation risk by slimy sculpins (Cottus cognatus): Responses to alarm, disturbance, and predator cues. Journal of Chemical Ecology 27:533-546. DOI: 10.1023/a:1010332820944.

Caro TM. 1995. Pursuit-deterrence revisited. Trends in Ecology \& Evolution 10:500-503. DOI: 10.1016/S0169-5347(00)89207-1.

Chang C., Li C-Y., Earley RL., Hsu Y. 2012. Aggression and Related Behavioral Traits: The Impact of Winning and Losing and the Role of Hormones. Integrative and Comparative Biology 52:801-813. DOI: 10.1093/icb/ics057.

Chivers DP., Brown GE., Ferrari MCO. 2012. The evolution of alarm substances and disturbance cues in aquatic animals. In: Brönmark C, Hansson L-A eds. Chemical Ecology in Aquatic Systems. Oxford: Oxford University Press,.

Chivers DP., Brown GE., Smith RJF. 1996. The evolution of chemical alarm signals: attracting predators benefits alarm signal senders. The American Naturalist 148:649-659. 
470 Chivers DP., Smith RJF. 1994. The role of experience and chemical alarm signalling in predator

471

472

473

474

475

476

477

478

479

480

481

482

483

484

485

486

487

488

489

490

491

492

493

494

495

496

497

498

499

500

501

502

503

504

505

506

507

508

509

510

511

512

513

514

515 recognition by fathead minnows, Pimephales promelas. Journal of Fish Biology 44:273285.

Dawkins R., Krebs JR. 1979. Arms races between and within species. Proceedings of the Royal Society of London. Series B, Biological sciences 205:489-511.

DeBose JL., Nevitt GA. 2008. The use of odors at different spatial scales: Comparing birds with fish. Journal of Chemical Ecology 34:867-881. DOI: 10.1007/s10886-008-9493-4.

Ellis T., James JD., Stewart C., Scott AP. 2004. A non-invasive stress assay based upon measurement of free cortisol released into the water by rainbow trout. Journal of Fish Biology 65:1233-1252. DOI: 10.1111/j.0022-1112.2004.00499.x.

Elvidge CK., Brown GE. 2012. Visual and chemical prey cues as complementary predator attractants in a tropical stream fish assemblage. International Journal of Zoology 2012:1-7. DOI: $10.1155 / 2012 / 510920$.

Endler JA. 1991. Interactions between predators and prey. In: Behavioural ecology: an evolutionary approach 3. Oxford, UK: Blackwell Scientific, 169-196.

Fast MD., Muise DM., Easy RE., Ross NW., Johnson SC. 2006. The effects of Lepeophtheirus salmonis infections on the stress response and immunological status of Atlantic salmon (Salmo salar). Fish \& Shellfish Immunology 21:228-241. DOI: http://dx.doi.org/10.1016/j.fsi.2005.11.010.

Ferrari MCO., Wisenden BD., Chivers DP. 2010. Chemical ecology of predator-prey interactions in aquatic ecosystems: a review and prospectus. Canadian Journal of Zoology 88:698-724. DOI: 10.1139/z10-029.

Gross HP. 1978. Natural selection by predators on the defensive apparatus of the three-spined stickleback, Gasterosteus aculeatus. Canadian Journal of Zoology 56:398-413.

Harvey MC., Brown GE. 2004. Dine or dash?: Ontogenetic shift in the response of yellow perch to conspecific alarm cues. Environmental Biology of Fishes 70:345-352. DOI: 10.1023/B:EBFI.0000035432.12313.87.

Hazlett BA. 1990. Source and nature of disturbance-chemical system in crayfish. Journal of Chemical Ecology 16:2263-2275.

Jentoft S., Aastveit AH., Torjesen PA., Andersen Ø. 2005. Effects of stress on growth, cortisol and glucose levels in non-domesticated Eurasian perch (Perca fluviatilis) and domesticated rainbow trout (Oncorhynchus mykiss). Comparative Biochemistry and Physiology Part A: Molecular \& Integrative Physiology 141:353-358. DOI: http://dx.doi.org/10.1016/j.cbpb.2005.06.006.

Jordão LC. 2004. Disturbance chemical cues determine changes in spatial occupation by the convict cichlid Archocentrus nigrofasciatus. Behavioral Processes 67:453-459.

Kiesecker JM., Chivers DP., Marco A., Quilchano C., Anderson MT., Blaustein AR. 1999. Identification of a disturbance signal in larval red-legged frogs, Rana aurora. Animal Behaviour 57:1295-1300. DOI: http://dx.doi.org/10.1006/anbe.1999.1094.

Lima SL., Dill LM. 1990. Behavioral decisions made under the risk of predation: a review and prospectus. Canadian Journal of Zoology 68:619-640. DOI: 10.1139/z90-092.

Lönnstedt OM., McCormick MI. 2015. Damsel in distress: captured damselfish prey emit chemical cues that attract secondary predators and improve escape chances. Proceedings of the Royal Society of London B: Biological Sciences 282.

Lönnstedt O., McCormick M., Chivers D. 2012. Well-informed foraging: damage-released chemical cues of injured prey signal quality and size to predators. Oecologia 168:651-658. 
516

517

518

519

520

521

522

523

524

525

526

527

528

529

530

531

532

533

534

535

536

537

538

539

540

541

542

543

544

545

546

547

548

549

550

551

552

553

554

555

556

557

558

559

560

561

DOI: $10.1007 / \mathrm{s} 00442-011-2116-8$.

Lunt J., Smee DL. 2015. Turbidity interferes with foraging success of visual but not chemosensory predators. PeerJ 3:e1212.

Mathis A., Chivers DP., Smith RJF. 1993. Population differences in responses of fathead minnows (Pimephales promelas) to visual and chemical stimuli from predators. Ethology 93:31-40. DOI: 10.1111/j.1439-0310.1993.tb00976.x.

Mathis A., Chivers DP., Smith RJF. 1995. Chemical alarm signals: predator deterrents or predator attractants? American Naturalist:994-1005.

McLennan DA., Ryan MJ. 1997. Responses to conspecific and heterospecific olfactory cues in the swordtail Xiphophorus cortezi. Animal Behaviour 54:1077-1088.

Mirza RS., Chivers DP. 2002. Behavioural responses to conspecific disturbance chemicals enhance survival of juvenile brook charr, Salvelinus fontinalis, during encounters with predators. Behaviour 139:1099-1110.

Moore FL., Evans SJ. 1999. Steroid hormones use non-genomic mechanisms to control brain functions and behaviors: A review of evidence. Brain, Behavior and Evolution 54:41-50.

Ness JH., Foster SA. 1999. Parasite-associated phenotype modifications in threespine stickleback. Oikos:127-134.

Olivotto I., Mosconi G., Maradonna F., Cardinali M., Carnevali O. 2002. Diplodus sargus interrenal-pituitary response: chemical communication in stressed fish. General and Comparative Endocrinology 127:66-70. DOI: http://dx.doi.org/10.1016/S00166480(02)00024-2.

Olsson O., Brown JS. 2006. The foraging benefits of information and the penalty of ignorance. Oikos 112:260-273. DOI: 10.1111/j.0030-1299.2006.13548.x.

Øverli Ø., Kotzian S., Winberg S. 2002. Effects of Cortisol on Aggression and Locomotor Activity in Rainbow Trout. Hormones and Behavior 42:53-61. DOI: 10.1006/hbeh.2002.1796.

Pottinger TG., Cook A., Jürgens MD., Sebire M., Henrys PA., Katsiadaki I., Balaam JL., Smith AJ., Matthiessen P. 2011. Indices of stress in three-spined sticklebacks Gasterosteus aculeatus in relation to extreme weather events and exposure to wastewater effluent. Journal of Fish Biology 79:256-279.

Scott AP., Ellis T. 2007. Measurement of fish steroids in water - a review. General and Comparative Endocrinology 153:392-400. DOI: http://dx.doi.org/10.1016/j.ygcen.2006.11.006.

Sebire M., Katsiadaki I., Scott AP. 2007. Non-invasive measurement of 11-ketotestosterone, cortisol and androstenedione in male three-spined stickleback (Gasterosteus aculeatus). General and Comparative Endocrinology 152:30-38. DOI: http://dx.doi.org/10.1016/j.ygcen.2007.02.009.

Smith RJF. 1992. Alarm signals in fishes. Reviews in Fish Biology and Fisheries 2:33-63. DOI: 10.1007/BF00042916.

Sogard SM. 1997. Size-selective mortality in the juvenile stage of teleost fishes: a review. Bulletin of Marine Science 60:1129-1157.

Stauffer H-P., Semlitsch RD. 1993. Effects of visual, chemical and tactile cues of fish on the behavioural responses of tadpoles. Animal Behaviour 46:355-364. DOI: http://dx.doi.org/10.1006/anbe.1993.1197.

Toa DG., Afonso LOB., Iwama GK. 2004. Stress response of juvenile rainbow trout (Oncorhynchus mykiss) to chemical cues released from stressed conspecifics. Fish 
562
Physiology and Biochemistry 30:103-108. DOI: 10.1007/s10695-005-0266-5.

Turesson H., Brönmark C. 2004. Foraging behaviour and capture success in perch, pikeperch and pike and the effects of prey density. Journal of Fish Biology 65:363-375. DOI: 10.1111/j.0022-1112.2004.00455.x.

Vavrek MA., Brown GE. 2009. Threat-sensitive responses to disturbance cues in juvenile convict cichlids and rainbow trout. Annales Zoologici Fennici 46:171-180. DOI: $10.5735 / 086.046 .0302$.

Vavrek MA., Elvidge CK., DeCaire R., Belland B., Jackson CD., Brown GE. 2008. Disturbance cues in freshwater prey fishes: do juvenile convict cichlids and rainbow trout respond to ammonium as an "early warning" signal? Chemoecology 18:255-261. DOI: 10.1007/s00049-008-0412-5.

Le Vin AL., Mable BK., Arnold KE. 2010. Kin recognition via phenotype matching in a cooperatively breeding cichlid, Neolamprologus pulcher. Animal Behaviour 79:1109-1114. DOI: 10.1016/j.anbehav.2010.02.006.

Wisenden BD., Chivers DP., Smith RJF. 1995. Early warning in the predation sequence: a disturbance pheromone in Iowa darters (Etheostoma exile). Journal of Chemical Ecology 21:1469-1480.

Wisenden BD., Thiel TA. 2002. Field verification of predator attraction to minnow alarm substance. Journal of Chemical Ecology 28:433-438.

Woodland DJ., Jaafar Z., Knight M-L. 1980. The "pursuit deterrent" function of alarm signals. The American Naturalist 115:748-753. DOI: 10.1086/283596.

Wyatt TD. 2010. Pheromones and signature mixtures: defining species-wide signals and variable cues for identity in both invertebrates and vertebrates. Journal of comparative physiology. A, Neuroethology, sensory, neural, and behavioral physiology 196:685-700. DOI: 10.1007/s00359-010-0564-y. 
Figure 1 (on next page)

Schematic of experimental tanks

Pump system A allowed transfer of fresh water or cortisol solution into the perch tank. Pump system B allowed transfer of the natural chemical cues from the stickleback holding water. 
Preference

Sticklebacks

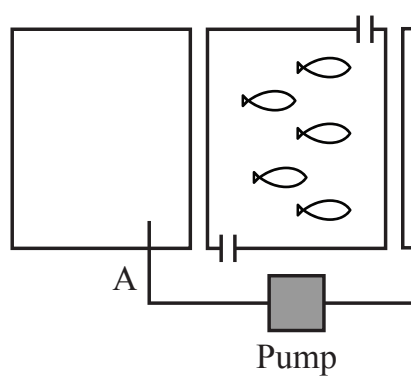

Preference

Zone

Sticklebacks

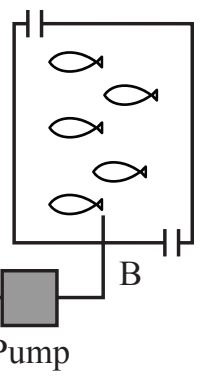




\section{Figure 2 (on next page)}

Scatter dot plots showing how chemical cues influenced perch behavior

Scatter dot plots showing median \pm inter-quartile range of (a) the proportion of total time spent by perch in chemical stimulus zone, (b) the proportion of time spent by perch orientating toward sticklebacks in the chemical stimulus zone, and (c) the proportion of lunges at sticklebacks in the chemical stimulus zone. 

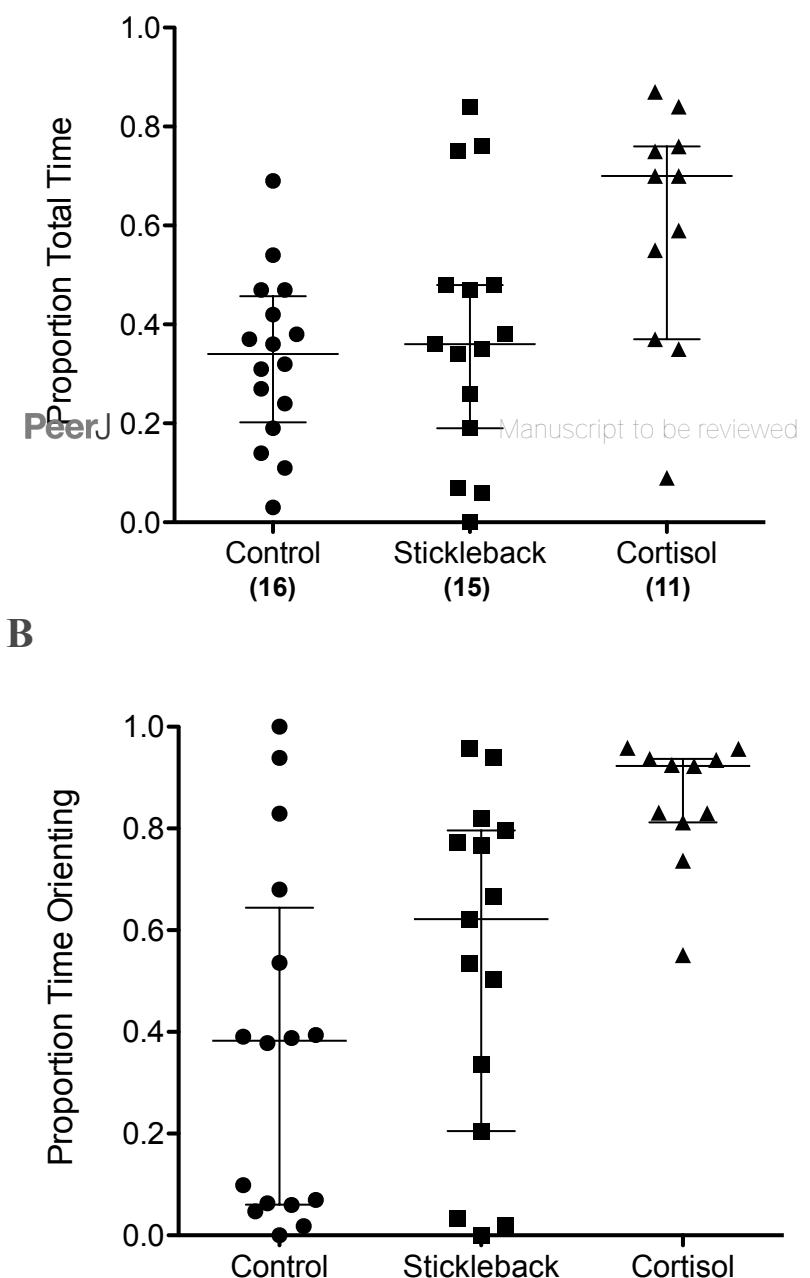

(16)

(15)

(11)

C

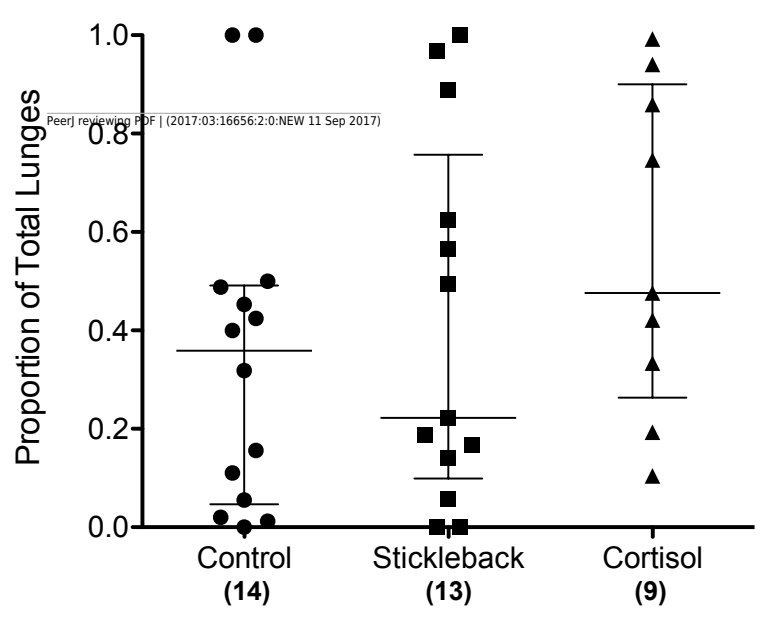




\section{Figure 3 (on next page)}

Scatter dot plots showing how chemical cues influenced perch behavior

Scatter dot plots showing median \pm inter-quartile range of $(a)$ the total lunges by perch at sticklebacks in the chemical stimulus zone, and (b) total movements between zones by perch. $n=$ control, 16; stickleback natural cues, 15; cortisol, 11. 
$\mathbf{A}$

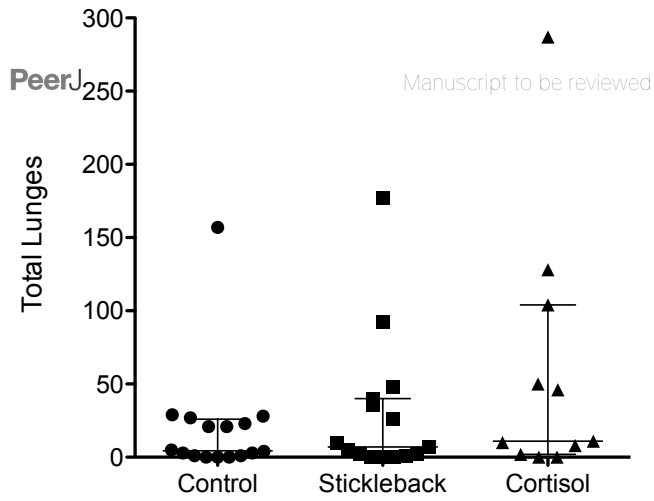

B

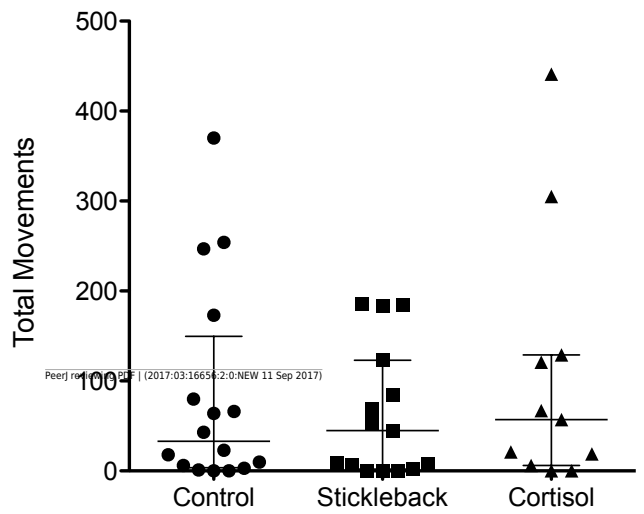




\section{Table $\mathbf{1}$ (on next page)}

Table of LMMs results

Linear Mixed Models testing the effect of chemical trial upon proportion of time in chemical stimulus zone, proportion of time orienting in chemical stimulus zone, and proportion of lunges in chemical stimulus zone. Individual ID was included as a random factor in all models. Values in bold denote statistically significant factors, * denotes marginally non-significant factor. 


\begin{tabular}{|c|c|c|c|c|c|}
\hline Treatments & & & & & $\begin{array}{l}\text { Random } \\
\text { intercept }\end{array}$ \\
\hline & $\beta$ & s.e. & $t$ & $\mathrm{P}$ & $\% \sigma$ \\
\hline $\begin{array}{l}\text { Proportion of time in } \\
\text { chemical stimulus zone }\end{array}$ & 0.33 & 0.09 & 3.61 & 0.001 & 35.8 \\
\hline
\end{tabular}

Proportion of time

$\begin{array}{llllll}\text { orienting in chemical } & 0.62 & 0.16 & 3.93 & <\mathbf{0 . 0 0 1} & 2.0 \mathrm{e}-03\end{array}$

stimulus zone

Proportion of lunges in

$\begin{array}{lllll}0.32 & 0.17 & 1.93 & 0.07 * & 50.8\end{array}$

chemical stimulus zone 